\title{
Correspondencia conservada de Eduardo Blanco-Amor a Federico García Lorca
}

\author{
Preserved correspondence of Eduardo Blanco-Amor to \\ Federico García Lorca
}

\author{
Roger TINNELL \\ Catedrático Emérito, University System of New Hampshire (EEUU) \\ rogtin@yahoo.es
}

[Recibido, xullo 2010; aceptado, setembro 2010]

\section{RESUMEN}

Cinco documentos ( 3 cartas, 2 tarjetas postales y una tarjeta de visita) mandados por Eduardo Blanco-Amor a Federico García Lorca han sido parcialmente editados. Aquí por primera vez presentamos esta correspondencia entera y con notas explicativas.

PALABRAS ClaVE: Eduardo Blanco-Amor, Federico García Lorca, cartas, correspondencia.

Tinnell, R., (2011): “Correspondencia conservada de Eduardo Blanco-Amor a Federico García Lorca”. Madrygal (Madr.), 14: 117-124.

\section{RESUMO}

Cinco documentos ( 3 cartas, 2 tarxetas postais e unha tarxeta de visita) enviados por Eduardo Blanco a Federico García Lorca foron parcialmente editados. Aquí presentamos a primeira correspondencia completa e notas.

PALABRAS CHAVE: Eduardo Blanco-Amor, Federico García Lorca, cartas, correspondencia

TinNell, R., (2011): “Correspondencia conservada de Eduardo Blanco-Amor a Federico García Lorca”. Madrygal (Madr.), 14: 117-124.

\begin{abstract}
Five documents ( 3 letters, 2 postcards and a carte de visite sent by Eduardo Blanco-Amor to Federico García Lorca have been published only partially. Here for the first time all five documents are presented whole and with explanatory notes.
\end{abstract}

KEY WORDS: Eduardo Blanco-Amor, Federico García Lorca, letters, correspondence.

Tinnell, R., (2011): "Preserved correspondence of Eduardo Blanco-Amor to Federico García Lorca". Madrygal (Madr.), 14: 117-124. 
En la Fundación Federico García Lorca se encuentran cinco misivas mandadas en 1934 y 1935 a García Lorca por su amigo Eduardo Blanco-Amor (Orense, 1897-Vigo, Pontevedra, 1979) ${ }^{1}$. Esta correspondencia está solo parcialmente publicada y aquí se presenta por primera vez completa y con notas explicativas.

En 1915 a la edad de 17 años, Blanco-Amor había empezado a trabajar como secretario de dirección y a colaborar con artículos para El Diario de Orense, y entre 1919 y 1929 residió en Buenos Aires ${ }^{2}$ donde desarrolló una gran actividad periodística como director de la publicación galleguista Céltiga. En Argentina y Uruguay colaboró en varias revistas gallegas y también en La Gaceta Literaria, Nós, y A Nosa Terra. En 1926 entró a formar parte del diario de Buenos Aires, La Nación, y en 1927 inició su carrera literaria, con la novela Os Nonnatos, a la que siguió, al año siguiente, el libro de poemas Romances Galegos. También fue director de la revista Galicia, publicada por el Centro Gallego de Buenos Aires. Regresó a España como corresponsal de La Nación (19291931). Residió en Madrid entre 1933 y 1935 donde fue redactor-jefe de la revista $\mathrm{Ciudad}^{3}$. Parece que Blanco-Amor y García Lorca se conocieron en España en 1933 después de la estancia triunfal del andaluz en Argentina y Uruguay. En Mayo de 1934 visitó a García Lorca en la Huerta de San Vicente en Granada:

Federico lleva a rastras a Granada como el presidiario sus grillos. [...] Yo fui a esperarle a Granada cuando regresó de Buenos Aires [...] Juntos pasamos aquellos días y visitábamos por la tarde el Casino [---] en el Casino estaban los viejos patricios [...] Uno de ellos le interrogó: Dicen que ustedes los poetas sois maricones. Y respondió Federico: ¿Y qué es poetas?" (citado en Armero, 233).
Ian Gibson escribe que durante su visita a Granada, Blanco-Amor "descubre a un Federico más íntimo del que andaba por la capital española [...y que...] podemos tener la seguridad de que, aquellos días en Granada, Lorca les contaría a sus dos confidentes [Blanco-Amor y Pepe García Carillo] ambos homosexuales, muchas anécdotas de su vida amorosa en Buenos Aires" (Gibson, 1987, 311-312).

En 1935, volvió Blanco-Amor a visitar a García Lorca en Granada y en la Huerta de San Vicente sacó varias fotografías ${ }^{4}$ del poeta y su familia (véanselas en Armero, 248-249). En el mismo año, 1935, Blanco-Amor ayudó en la preparación de Seis poemas galegos (Editorial Nós) de García Loca y prologó ${ }^{5}$ el libro. ¿Escribió estas poesías en gallego el poeta granadino o son el resultado de una colaboración entre Lorca, Blanco-Amor y Ernesto Pérez Güerra da Cal? En su edición de las obras completas de García Lorca, (Tomo I, 958-960), Miguel García Posada escribe de esta polémica y de las investigaciones hechas por el hispanista Andrew A. Anderson. Es seguro que Blanco-Amor y Güerra da Cal fueron útiles a la hora de componer los poemas en gallego ${ }^{6}$.

Sólo tenemos un fragmento de una carta que García Lorca le manda a Blanco-Amor en la cual García Lorca le escribe que está leyendo los Romances galegos: "Estoy leyendo tu libro, tus romances antípodas. ... ¡Qué idioma!, ¡qué riqueza esta de nuestra España! ¿Por qué tendría que morir esa antigua maravilla?" (Epistolario completo, 601).

Abiertamente homosexual, Blanco-Amor escribía francamente de su propia sexualidad y es importante la relación con el también homosexual García Lorca ${ }^{7}$.

Ian Gibson, el biógrafo de García Lorca, escribe de los dos escritores: "Su homosexualidad, a

\footnotetext{
${ }^{1}$ Blanco-Amor fue periodista, poeta y novelista, profesor de la Facultad de Humanidades de Uruguay y de la Escuela Internacional de Temporada en Santiago de Chile, y director del Teatro Español de Cámara de Buenos Aires.

2 Véanse una fotografía de Eduardo Blanco-Amor "convaleciente" en Buenos Aires, 1928, y otras dos sacadas en Rabat en el verano de 1935 (las tres archivadas en los archivos de la Diputación de Ourense) en el catálogo de la exposición en el Museo Nacional Centro de Arte Reina Sofía, Federico García Lorca (1898-1936), 212 y 322.

3 Ciudad, La "Revista de Madrid para toda España", fue dirigida por Víctor de la Serna. Entre sus páginas salieron Manuel Abril, Carmen Conde, García Lorca, Benjamín Jarnés, Alfonso Reyes y muchos más.

${ }^{4}$ Sobre Blanco-Amor y la fotografía, véase Carlos Lema.

5 Véaselo en García Lorca, Obras completas, Tomo I, 871-874.

6 "Su colaboración en ellos [Seis poemas galegos], así como la de Pérez Güerra da Cal, es indudable” (Ian Gibson, 2009, 302). Véase, también Gibson, 1987, 359-360.

7 "Tema que debe estudiarse preferentemente desde a súa obra e con testemuños directos do autor" (Pérez Rodríguez). Román Gubern escribe (126) de los gays (Luis Cernuda, Benjamín Palencia, Juan Gil-Albert, Vicente Aleixandre, Gustavo Durán y Eduardo Blanco-Amor) "compañeros de [la] constelación cultural de García Lorca”.
} 
diferencia de la del poeta, era ostentosa, bastante camp y nada cauta, y algunos amigos de Federico [...] se sentían ofendidos por sus modales, que les parecían insolentes y hasta vulgares. Lorca no les hizo caso [...] y llegó a considerarle divertido y estimulante" (Gibson, 2009, 298). Fue "de los íntimos amigos de Lorca, quien más abogó porque la crítica tuviera en cuenta la homosexualidad del poeta" (Gibson, 2009, 306). El biógrafo cita unas notas que Blanco-Amor escribió en 1978:

Algún día habrá que rescatar a FGL de las veladuras que enturbian su genio y dejan inexplicables la raíz y floración de su vida-obra. Quienes le hemos conocido y, por conocido, amado, no podemos dejarnos morir llevándonos dentro la pudrición de esta complicidad; de un silencio que juzgarán cobardía que quienes vengan en tiempos de mayor naturalidad y más desasida inteligencia para entender y juzgar a sus semejantes, semejantes en más de un sentido (citado en Gibson, 1987, 22; Gibson, 2009, 307).

Correspondencia de Blanco-Amor a García Lorca

1. [Carta autógrafa. 1 folio, ambas caras, escritas a plumilla. Membrete de Eduardo BlancoAmor $]^{8}$

\section{5 de Nbre 1934 \\ Querido Federico:}

Te he llamado diversas veces por teléfono y fui varias también al Anfisturium ${ }^{9}$ con el mismo fin. - Ya me despido de encontrarte hasta el Juicio Final.- Siento que me falta la enorme cantidad de abnegación necesaria, para ser amigo tuyo -No es que tú seas malo, ni egoísta, ni desafecto como dicen por ahí los que no tienen méritos para estar en tu corazón, para conocer tu corazón. Sencillamente te falta vida, tiempo. - Para ser tu amigo en presencia y actividad, hay que tener 0 una personalidad muy fuerte para deslumbrarte o una falta de personalidad absoluta para no haber cuenta de tus dramáticas o inevitables (inevitables para ti mismo, claro está) zambullidas en el no ser, en un mundo mágico y desconocido, al que te [vas--tachado] evades, envuelto en la capa de Fierabrás ${ }^{10}$ que has tenido la suerte de adquirir en un Rastro de gitanas brujas. Me conformo, pues, con ser tu amigo en pasividad y en ausencia... Ya sabes que la mejor poesía del alma de mi raza es la "voluntad de la re $[\mathrm{g}]$ signación". -

Comprenderás que no te escribo solamente para endilgarte este tratado de etnopsicología comparada. Te escribo - y te buscaba para lo mismo - a fin de hacerte conocer el artículo de Romay ${ }^{11}$ que he pedido a Buenos Aires y que hace unos días me llegó. - La cosa no es tan fuerte como yo creía - no hay más alusión que las líneas subrayadas. - ¿Qué te parece?

Cuando tengas algún tiempo libre, excava en la montaña de tus papeles y búscame la arenita de aquel cuento de Nebraska ${ }^{12}$, que me gustaría tener. -- Lo metes en un sobre y me lo mandas. Yo te mando en éste, junto con esta inocente homilía, mis brazos con la cordialidad de siempre para siempre, a pesar de tu "yo" aparencial.

Eduardo

t/c Gómez de Baquero, 13-1 ${ }^{\circ}$

Teléfono 26024. -

2. [Tarjeta de visita autógrafa escrita al dorso a plumilla. CIVDAD Revista de Madrid para toda

8 En Christian De Paepe, núm. M-Lorca COA-120. Parcialmente publicada por Maurer, 80, y por Luis Pérez Rodríguez.

9 El Club Teatral de Cultura Anfistora (Madrid, 1933-1936) fundada por Pura Maórtua de Ucelay. Véase Bonet, 165.

${ }^{10}$ Caballero de gigantesca estatura que figura en varios cantares de gesta franceses. Hijo del almirante Balán, rey de Al-Andalus. El texto más antiguo de la leyenda de Fierabrás es del siglo XII. Calderón de la Barca utilizó elementos de la historia en su La puente de mantible. El "bálsamo de Fierabrás" es una poción mágica capaz de curar todas las dolencias del cuerpo humano (cuando el rey Balán y su hijo Fierabrás conquistaron Roma, robaron en dos barriles los restos del bálsamo con que fue embalsamado el cuerpo de Jesucristo que tenía el poder de curar las heridas a quien lo bebía). En el capítulo X del primer volumen de Don Quijote de la Mancha de Cervantes, Don Quijote le dice a Sancho Panza que él conoce la receta del bálsamo. En el capítulo XVII, el caballero hierve los ingredientes (aceite, vino, sal y romero) y los bendice con ochenta padrenuestros, ochenta avemarías, ochenta salves y ochenta credos. Al beberlo, Don Quijote padece vómitos y sudores pero se siente curado después de dormir. Para Sancho Panza tiene un efecto laxante, justificado por Don Quijote por no ser caballero andante.

11 Francisco L. Romay (1882-1972) fue Comisario Inspector de la Policía Federal Argentina. Redactor y director de El Argentino, tuvo trato asiduo con Alfonsina Storni, Carlos Gardel y con otros artistas e intelectuales de la época. Autor de Antiguos servicios policiales (1939) y de Historia de la Policía Federal (1963), fue uno de los creadores del Diccionario Histórico Argentino (1953). Donó los 6.000 volúmenes de su biblioteca personal a la Policía Federal. El artículo mencionado por Blanco-Amor con "las líneas subrayadas" no se ha conservado en el archivo de la Fundación Lorca. Véanse en la Red, por ejemplo:

http://www.quienesgardel.com.ar/trabajos/fromay.html y

http://www.quienesgardel.com.ar/trabajos/comisario.html.

12 El "cuento de Nebraska" no se ha conservado. 
España Eduardo Blanco-Amor Redactor-Jefe $]^{13}$ [23 de diciembre 1934]

\section{Querido Federico:}

Ahí va nuestro prodigioso fotógrafo Aracil ${ }^{14}$. - Trátalo como lo que es, un

artista, y preséntaselo a [Manuel] Fontanals ${ }^{15}$. - Elegid juntos las escenas y mandadme cosas lindas.
Abrazos
Eduardo
28-XII-34. - 16

3. [Carta autógrafa. 1 hoja, papel de carta escrita a plumilla. Membrete: Grand-Hotel Logroño. Propietarios Esteban y Trocóniz. Teléfono, 1409. Recomendamos en Salamanca El Grand Hotel Sucursal de esta casa $]^{17}$

[22 de Septiembre de 1935]

\section{Querido Federico:}

¡Mira donde he venido a parar, hombre! Me han traído unos amigos indianos; pues, a su paso por Vigo, oyeron decir, por casualidad, que unos oficialillos iban a agredirme en pandilla y vestidos de paisano. ¿Qué valientes!

Tu libro ${ }^{18}$, lo dejé en marcha; y si no hubiera sido por este asunto y por el proceso que me hizo dejar Santiago a los tres días de llegar, ya estaría listo para fin

de mes. Aquí estaré con esta familia hasta el día 26 o 27.- Ya me enteré del venturoso escándalo de "Yerma" • ¿Qué te decía yo? Es muy grande, muy generosa y muy inteligente esa Barcelona. Me sumo de todo corazón el ¡Visca Catalunya! de Margarita $[\mathrm{Xirgu}]^{20}$ que supongo lo habrá dada en catalán. Y si estas derechas cabronas siguen impidiéndonos rehacer lógicamente a España, entonces yo gritaré también

¡Visca Catalunya lliure!

Por lo menos, que de todo este hundimiento, este asco y esta catástrofe, se salve un regazo de España que diga al mundo que, a pesar de todas las apariencias, hubo en este país un pueblo civilizado.

Te abrazo con todo mi cariño y te felicito con toda mi razonada admiración.- Y me felicito a mí mismo, porque, esta vez, tampoco me falló la profecía. -

Si no estuviese tan pobre, iría a acompañarte un par de días a ésa. Pero con estos disgustos, no escribo nada.?- Y a pesar de mi sapientísima administración, claro el dinero se termina.- Todo esto me pone muy triste $y$ tengo ganas de llorar y de marcharme. Por desgracia mientras no termine el proceso en que me han metido carcas y milites, no podré irme.- Ahora los lerrouxistas ${ }^{21}$ gallegos, me buscan para la campaña electoral y

${ }^{13}$ Inédita. En Christian De Paepe, núm. M-Lorca COA-121. La "Casida de los ramos" del Diván del Tamarit apareció en Ciudad en Diciembre 1934.

14 ¿Ángel Aracil? Según se cita en Historia de la fotografía española, 1839-1986 (Actas del I Congreso de Historia de la Fotografía Española, Sevilla, 1986), 82, Ángel Aracil fue vicepresidente de la Unión Fotográfica. En el índice del citado libro figura como fotógrafo de Zaragoza y 1929 como año de trabajo en activo. Le agradezco esta información a Belén Palacios Somoza, Servicio de Dibujos y Grabados de la Biblioteca Nacional de España. En el Fondo Fotográfico de la Universidad de Navarra se encuentra una fotografía firmada por "Aracil", el retrato de un niño en su primera comunión, realizada hacia 1950. Fotografías firmadas por "Aracil" aparecen en la "revista nacional de la Falange", Vértice, números 1-8 (1937) y en núm. 30-31 (abril 1940). La escultura por Emilio Aladrén de José Antonio aparece en una foto de "Aracil" en el núm. 4 de Vértice (julio-agosto 1937). Véasela en José Carlos Mainer, www.uv.es/imagengc/articulos/La\%20construccion\%20de\%20Franco.pdf.

Honorio García Condoy conoció a su esposa en la garita de fotografía del fotógrafo Aracil, amigo del escritor. Véase "El escultor Honorio García Condoy. Homenaje en el centenario de su nacimiento", Zaragoza, 2000, en la red: http://www.redaragon.com/ trebede/nov2000/articulo2.asp.

En la red se anuncia la venta de una fotografía del General Francisco Franco firmada por Ángel Aracil. Lote 19592579 en www.todocoleccion.net.

${ }_{15}$ Manuel Fontanals (1895-1972), escenógrafo, figurinista, ilustrador y cartelista. Colaboró en varias obras de Lorca.

16 Blanco-Amor estuvo presente en el estreno de Yerma en el Teatro Español el 29 de Diciembre de 1934 (Gibson, 1987, 336).

17 En Christian De Paepe, núm. M-Lorca COA-122. Parcialmente publicada por Maurer, 83, y por L. Pérez Rodríguez

${ }^{18}$ Una referencia al libro Seis poemas galegos que saldría poco después.

19 Con la compañía de Margarita Xirgu, Yerma se estrenó en el Teatro Barcelona el 17 de Septiembre 1935.

${ }^{20} \mathrm{La}$ actriz catalana Margarita Xirgu y García Lorca se conocieron en 1926 y esta gran amiga del poeta-dramaturgo estrenó Mariana Pineda (Barcelona, 1927), La zapatera prodigiosa (Madrid, 1930), Yerma (Madrid, 1934) y Doña Rosita la soltera (Barcelona, 1935), y reestrenó Bodas de sangre (Barcelona, 1935). En 1941 montó La casa de Bernarda Alba en Chile.

${ }^{21}$ Alejandro Lerroux García (1864.1949), político español, fue director de El País y fundó El Radical. Encarcelado por sus campañas contra la guerra de Cuba y el proceso de Montjuic. Se trasladó a Barcelona en 1899 donde dirigió La Publicidad y fundó El Progreso y El Intransigente. Elegido diputado a Cortes. En 1908 fundó el nuevo Partido Radical. Fue ministro de Estado en el gobierno provisional presidido por Alcalá Zamora y en el de Azaña pero salió de él en diciembre de 1931 por su oposición a los socialistas. Después de la caída de Azaña, presidió el Consejo de Ministros y después de las elecciones de noviembre formó un nuevo gobierno. Caído en Abril de 1934, fue otra vez presidente del Consejo de Ministros, Ministro de Estado en el gobierno Chapaprieta (sept.-oct. 1935). Rodeado de 
me ofrecen prebendas y dinero.- Pero no he

flaqueado en mi época abundante, menos lo haré ahora en la pobreza.- Yo soy de los que se crecen en la adversidad. ¡Pero esta tristeza, esta tristeza que no me deja serenidad para trabajar-!

Solo te pido una postal a vuelta de correo mandándome las señas de tu cuñado ${ }^{22}$, para mandar a tu mamá las fotos, que ya las tengo, dedicadas y todo, y no quisiera irme con ellas ${ }^{23}$.-Si me escribes hoy mismo, hazlo a las señas de este hotel. Y debes de escribirme, porque estoy muy triste.-

Saludos cariñosos a ese buen amigo que es [Cipriano] Rivas Cherif ${ }^{24}$ y también muy respetuosos a Margarita Xirgú y tú un abrazo de

Eduardo

Logroño - 22-IX-35

4. [Tarjeta postal autógrafa escrita a plumilla. Fotografía de lavanderas. Vigo.- Alrededores. G. H. Alsina-Madrid 33. Matasellos, Vigo Pontevedra, Nov. 6, 1935] ${ }^{25}$

\section{Sr. D. Federico García Lorca}

Alcalá 102 - $4^{\circ}$

Madrid

Ahora mismo, dentro de 10 minutos, me embarco.

Abrazos

Eduardo

Uno de estos días, te mandan tu libro ${ }^{26}$.

5. [Carta mecanografiada. 2 hojas. Adiciones y supresiones a máquina y a plumilla. Firma autógrafa]

[29 de Noviembre de 1935$]^{27}$

\section{Mi querido Federico:}

Perdona que te escriba a máquina, pero son tantísimas las cosas que tengo que hacer que apenas tengo tiempo. Te diré todas las cosas lo más brevemente posible. Primero que ando sufriendo tan horriblemente que no sé como puedo sobrevivirme. En realidad me invento cada mañana de esta desolación que me es cada día. - Ya te supondrás lo ocurrido. Yo vine a Buenos Aires más que por nada, a buscar a quien estaba en mi corazón y en mi carne después de un beso que duró siete años, con sus noches, sus mares y sus angustias. Pues este abrazo que yo traía temblando en mis músculos, con un ansia de tanta ausencia junta, no encontró ni siquiera el fantasma piadoso de esas mentiras que se nos cuentan para que sigamos viviendo. Nada. Una confesión bruta, a la media hora de desembarcar, y otra persona en medio. Un horror, Federico querido. No sé ni siquiera como te lo cuento. Van pasados diez días y este espanto con todos sus insomnios, esperanzas que arden como papeles, proyectos sin sentido y venganzas sin valor siquiera teórico, me traen y me llevan como un mar. - De pronto me quedo con la vida vacía entre las manos y todo desmoronado dentro y fuera de mí.- En contraste con esta brutalidad, para que sea más dolorosa, está el aire imprevisto de triunfo con que Buenos Aires me recibe de nuevo. Los periódicos hablando de mí y publicando interviús políticas durante una semana entera. Proposiciones de todas partes para escuchar mi palabra. Requerimientos para que acepte recepciones. Pedidos de colaboración... ¡Hasta veladas cartas de amor, todas temblorosas de adolescencia, con un aire muy suave de barrios grises y tristes que confinan con los álamos y sauces del río! Y yo desmoronado en este cuarto de un hotel feo, todo rumoroso con las cohabitaciones de los matrimonios nacidos del fragor de las razones sociales, que vienen a Buenos Aires a rehacer cierta luna de miel antigua y a comprar madapolanes y cacerolas. -Procuro [palabra tachada] no morirme [escrita a plumilla] arrimando a la hoguera toda mi voluntad. Alfonso, con quien me he explayado, hace todo lo posible para distraerme. Por su consejo salgo mañana para Córdoba a pasar unos días con una familia amiga. Si después estoy más sereno, aceptaré la proposición de la estación

escándalos, perdió la mayoría de sus escaños en las elecciones de 1936. En Julio de 1936 huyó a Portugal desde donde apoyó la insurrección militar.

${ }^{22}$ Manuel Fernández-Montesinos Lustau (1902-1936), marido de Concepción (Concha) García Lorca, hermana del poeta.

${ }^{23}$ Serán las fotografías que sacó Blanco-Amor en la Huerta de San Vicente.

24 Cipriano Rivas Cherif (Madrid, 1891-México, 1967), escritor y director teatral. Íntimo amigo de García Lorca, dirigió en 1927 a Margarita Xirgu en Mariana Pineda (Madrid, Teatro Español), La zapatera prodigiosa en 1930 y Yerma en 1934-35. Trabajó también con Lorca en La Barraca.

${ }^{25}$ En Christian De Paepe, núm. M-Lorca COA-123. Parcialmente publicada por Maurer, 83-84. Blanco-Amor sale para Buenos Aires.

26 Seis poemas galegos.

27 En Christian De Paepe, núm. M-Lorca COA-124. Parcialmente publicada por Maurer, 84, Gibson, 2009, 305-306, y por Luis Pérez Rodríguez. 
nueva de radio, "EI Mundo", que es maravillosa y que tiene muy selectos programas. - A propósito de esto pienso dedicar tres de las charlas al tema que tengo pensado para un libro: "Excursión a García Lorca". Me haría[n] tanta falta como morir, algunos de tus poemas del libro de Nueva York, que como es natural no me mandarás. Y harás muy mal. Te lo digo por si Dios consiente que seas alguna vez buen amigo de ti mismo y se te ocurre mandármelos. Al día siguiente de llegar yo, salió el artículo sobre Da. Rosita, que hizo profunda sensación. Se considera "como la revelación de un crítico teatral de primer orden". ;Ganas de hablar! [Eduardo] Mallea $^{28}$, en cuanto [palabra tachada] entré en "La Nación" para saludarle, me dijo: "Acaba Vd. de dar una lección a todos los críticos del idioma, con este ensayo, culto, entretenido y sencillo [palabra tachada] siendo muy profundo, que se lee como un cuento. Haga Vd. renuncia a muchas cosas y sea Vd. el crítico de nuestra generación".A continuación hablamos de la obra, que yo les expliqué, precediéndola de una exposición sobre Granada y su estilo. Quedaron maravillados y deseando verla en escena. Le hablé de tus proyectos y realizaciones. Casi toda la conversación estuvo a ti dedicada. No hago más que corresponderte. Ahora veo cuanto ha hecho por mí y eso que apenas nos conocíamos. ¡Y hay quien dice que eres egoísta! En realidad tú has impuesto aquí mi nombre: porque lo cierto es que la gente me quería y esperaba de mí no sé que cosas, pero tú has atizado mucho de este fuego. Gracias, Federico. Ya sabes que yo soy sobrio en las expresiones de mis sentimientos, pero que me van muy hondo.-

En cuanto salga de estas cenizas, lo primero que aceptaré será la recepción en el CIRCULO DE LA PRENSA, a continuación de la cual pronunciaré una conferencia con este tema: Azaña. El hombre y la idea. Le expuse el plan de la misma a [Xavier] Bóveda ${ }^{29}$ y piensa él que será una cosa de mérito. Azaña despierta aquí una expectación tan formidable, que eso mismo hace fácil y temible a la vez el merodearlo con este intento de describir a su alrrededor [sic] un mero círculo de palabras.- Yo siento por Azaña un cariño sin límites y una admiración que me da miedo, porque invade una zona de mi ser, que siempre estuvo libre para mis [palabra tachada] paseos interiores: mi self control crítico. Yo tuve fanatizado muchas veces, casi toda la vida, mi corazón. Pero mi mente era mía. Ahora no. Estoy fanatizado integralmente. Esto me permite, sin yo haberlo querido, penetrarme de Azaña más que intelcuamlemente [sic], por medio de sutiles modos de conocimiento que más tiene que ver con la mística. De tal [modo, tachado] forma [escrita a plumi1la] es así, que cuando leo sus discursos o le oigo se ponen en movimiento dentro de mí una serie [de, escrita a plumilla] mociones y resonancias que ya me eran antiguas sin que yo las supiese en clara conciencia de sus palabras o ensueños exactos. $Y$ muchas veces mi contacto con él más parece monólogo que diálogo. Ya sé que todo esto parece gran presunción, pero es la verdad, y qué quieres tú que yo le haga...

El otro día nos encontramos Lola Membrives y yo en una fiesta. Me abrazó como antigua amiga y me agradeció los "magníficos viajes por España que había hecho, inmóvil, leyendo mis cosas".- Ardía en ganas de hablarme aparte. $Y$ como se trataba de una exhibición de "La Traviesa Molinera" 30 en privado, en cuanto se apagó la luz, nos sentamos juntos y empezamos a hablar de ti.- Está muy dolida y triste de ti. La conclusión de nuestra conversación fue ésta: Ya que no le has dado "Yerma" ni piensas darle Da. Rosita - con cuyo papel de criada sueña - que le destines por lo menos "Casa de Maternidad" ${ }^{11}$ o que le escribas cualquiera otra obra. Yo creo que debías hacerlo. Margarita [Xirgu] está por encima de estos menudos celos teatrales y no se enfadaría, porque Margarita no es actriz más que por su gran talento y su angustiosa sensibilidad. Es actriz de escena y no de entre bastidores. Ella misma te aconsejaría que atendieses el pedido de Lola. Está desolada y me dice que todo cuanto le leen, le parece de azucarillo o percalina; que sueña con hacer una de tus mujeres y que este año no tuvo interés en hacer temporada porque le faltaba el entusiasmo que solo tú puedes devolverle. Piensa un poco en esto y contéstame.- Pero contéstame. Soy aquí un poco tu representante

${ }^{28}$ Cuentista, ensayista y novelista, Eduardo Mallea (Bahía Blanca, Argentina, 1903-Buenos Aires, 1982) publica su primer cuento a los 17 años. En 1927 abandona los estudios para ingresar a la redacción del periódico La Nación donde por muchos años fue director del suplemento literario.

29 Xavier Bóveda (Orense 1898-Madrid, 1963), poeta modernista. Se instaló definitivamente en Buenos Aires en 1925 donde entre 1927-1929 dirigió la revista Síntesis. Véase Bonet, 116.

${ }^{30}$ La versión cinematográfica de El sombrero de tres picos de Pedro de Alarcón es de 1934, dirigida por Harry Abbadie D’Arrast con guión de Edgar Neville y Harry Abbadie D'Arrast.

${ }^{31}$ El título, tachado, aparece en la hoja inicial del borrador de la obra inconclusa Comedia sin título. Véase la lista de personajes de la también inconclusa Casa de maternidad en García Lorca, 1996, II, 768. 
espiritual y [dos palabras tachadas] pienso dedicarle tanto tiempo a mis cosas como a [valora, tachado] velar y a defender y a exaltar a las tuyas. Al fin, aunque mi vida no tuviese otro objeto que la de servir a la tuya, ya con esto estaría bien justificada. Toma las cosas, no te diré en serio, porque no aconsejo actitudes aburridas, pero por lo menos con cierto ritmo y orden.

Lo de Lola [Membrives] ahí queda, como lo más importante de esta carta. No desmorones el prestigio que me has creado ante ella, dejando mi carta sin respuesta.-

Y nada más. No porque no tengo un mundo más de cosas que decirte, sino porque ya no tengo humor para seguir escribiendo, ni sé como llegué a tanto.-

Dales grandes abrazos a [Cipriano] Rivas Cherif. Dile que en mis interviús hablé muchísimo de la T.E.A. ${ }^{32}$ y de su director y que dije que allí se estaba gestando "el nuevo tono técnico del teatro de España y de sus actores futuros, mucho de ellos ya presentes".-

Abrazos a Regino [Sáinz de la Maza $]^{33}$, a Iglesias $^{34}$, a del Moral... a todos los que, de buena fe, me habéis envenenado de España con aquella memorable noche de la bodega, que no puedo sacarme de las mientes. Y tú, Federico querido, ayúdame en este drama con tus palabras, que te lo agradeceré para siempre; pues me encuentro muy triste en esta soledad tan inútilmente habitada. Abrazos también a tu gente buenísima y uno muy grande para ti, de

Eduardo

Bs. Aires, nbre.29-935

Escríbeme a Calle Cevallos, 1030. [Dcha, tachado] $\mathbf{1}^{\circ}$ Dcha.-

[Anotación a lápiz de mano de García Lorca:] "-14037- M. Sierra"

\footnotetext{
${ }^{32}$ Cipriano Rivas Cherif puso en pie el Teatro Escuela de Arte (TEA) con la colaboración de Salvador Bartolozzi (quien hizo los decorados para La zapatera prodigiosa en 1930), Enrique Casal Chapí (entre 1933-1937, director musical de la TEA) y Felipe Lluch. Véase Bonet, 525 .

33 Regino Sáinz de la Maza (Burgos, 1896-Madrid, 1981), célebre guitarrista, compositor, ensayista, crítico musical y profesor. Véanse las misivas de Sáinz de la Maza a García Lorca en Tinnell, 2009, 81-100.

${ }^{34}$ Francisco Iglesias Brage (Ferrol, La Coruña, 1900 - Madrid, 1973), explorador, ingeniero, militar y famoso pionero de aviación.
} 


\section{BIBLIOGRAFÍA}

Anderson, Andrew A. (1988): "Who Wrote Seis poemas galegos And in What Language", en C. Brian Morris (ed.), "Cuando yo me muera..." Essays in Memory of Federico García Lorca. Lanham, Md. (EEUU): University Press of America.

Armero, Gonzalo (ed.) (1998): Federico García Lorca. Vida, en Poesía. Revista ilustrada de información poética. No. 43.

BlANCO-AMOR, Eduardo (1935): “Apostillas a una barbarie”, en El Defensor de Granada, 7 Julio 1935, p. 1.

- (1935): "Nueva obra teatral de García Lorca", en La Nación, Buenos Aires, 24 Noviembre 1935, p. 3 .

(1956): “Evocación de Federico”, en La Nación, Buenos Aires, 21 Octubre 1956.

(1959): "Los poemas gallegos de Federico García Lorca”, en Ínsula, Madrid, núms. 151-153, p. 9.

(1978): "Federico, otra vez; la misma vez", en El País, “Arte y pensamiento", Madrid, año II, núm. 5 (1 Octubre 1978), I, vi-vii.

Bonet, Juan Manuel (1995): Diccionario de las vanguardias en España, 1907-1936. Madrid: Alianza.

DE PAEPE, Christian (dir.) (2003): Catálogo general de los fondos documentales de la Fundación Federico García Lorca, Vol.VI, Catálogo de la correspondencia a Federico García Lorca. Con la colaboración de Rosa María Illán de Haro y Sonia González García. Madrid: Consejería de Cultura de la Junta de Andalucía, Fundación Federico García Lorca.

GARCíA LoRCA, Federico (1997): Epistolario completo. Andrew A. Anderson y Christopher Maurer (eds.). Madrid: Cátedra.

- (1996): Obras completas. Miguel García-Posada (ed.). Barcelona-Valencia: Galaxia GutenbergCírculo de Lectores.

- (1988): Seis Poemas galegos. Andrew A. Anderson (ed.). Madrid: Espasa Calpe.

Gibson, Ian (1987). Federico García Lorca. 2. De Nueva York a Fuente Grande 1929-1936. Barcelona: Grijalbo.

- (2009) Lorca y el mundo gay. Madrid: Planeta.

Gubern, Román (2007): “Las fuentes de 'Un perro andaluz' en la obra de Dalí”, en Ola Pepín! Dali, Lorca y Buñuel en la Residencia de Estudiantes. Madrid: Residencia de Estudiantes-Fundació Caixa Catalunya, pp. 79-136.

LEMA, Carlos (2009): "Desexo, fotografía e literatura en Blanco-Amor", Madrygal. (Madr.), 12, pp. 37 46.

MAURER, Christopher (1987): "De la correspondencia de García Lorca", Boletín de la Fundación Federico García Lorca, núm. 1, pp. 83-84.

Pérez RodríGuez, Luis (1994): “Cartas inéditas de Blanco Amor”, La Región (Orense), 15 de Noviembre 1994, p. 18.

Tinnell, Roger (2009): Los músicos escriben a Federico García Lorca (Epistolario conservado en la Fundación Federico García Lorca). Granada: Centro de Documentación Musical de Andalucía. 